\title{
Acoustic characterization of a forest fire event
}

\author{
D. X. Viegas ${ }^{1}$, L. P. Pita ${ }^{1}$, F. Nielsen ${ }^{2}$, K. Haddad ${ }^{2}$, \\ C. Calisti Tassini ${ }^{3}$, G. D'Altrui ${ }^{3}$, V. Quaranta ${ }^{4}$, I. Dimino ${ }^{4}$ \\ \& H. Tsangaris ${ }^{5}$ \\ ${ }^{I}$ Association for the Development of Industrial Aerodynamics, Coimbra, \\ Portugal \\ ${ }^{2}$ Bruel \& Kjoer, Ncerum, Denmark \\ ${ }^{3} D^{\prime}$ 'Appolonia S.p.A., Rome, Italy \\ ${ }^{4}$ Italian Aerospace Research Centre, Capua, Italy \\ ${ }^{5}$ University of Cyprus, Nicosia, Cyprus
}

\begin{abstract}
In this paper, a methodology to perform the acoustic characterization of a forest fire event is reported. A review of the influence of fuel type (litter, grass, shrubs, slash), fuel moisture, and weather factors on fire behaviour and on the relative acoustic spectrum has been carried out. Fire produced noise is basically due to periodic fluctuations of whirling structures at the fire's basis; these structures have natural low frequencies and are inversely proportional to fuel surface. The analysis of fire emission properties has been based upon laboratory and field testing, consisted of the burning of different fuels placed on tables or on field plots. The objectives of the trials have been the evaluation of fire acoustic spectra, with respect to the different fuel types and fire conditions. The frequency content of the acoustic signals has been evaluated; the results obtained have confirmed the main spectrum features reported in literature. Tests have also been made to evaluate the fire radiated heat to fibre optic sensors with cables in open air, buried or inside the flames, in order to characterise sensors behaviour with respect to fire, wind and smoke. The results of the tests have been used in the design phase of a new fire monitoring system made up of acoustic sensors, which is able to detect and track fires from the beginning, and fibre optic sensors, for a capillary monitoring of temperature in forest areas.
\end{abstract}

Keywords: forest fire, acoustic sensors, fibre optic sensors. 


\section{Introduction}

Forest fires represent a constant threat to ecological systems, infrastructure and human lives. Forest fire fighting is a very dangerous activity, which involves extensive human resources with many casualties every year. Apart from prevention measures, early detection and accurate monitoring remain the most effective ways to improve the effects of the extinguishing operation, to increase the probability of fire confining, and thus to reduce damage to people and goods, and also costs for emergency management. State of the art technology for fire detection is essentially based on thermal and infrared cameras and on remote sensing (Radke et al. [1]). Infrared and thermal cameras, in fixed monitoring systems, can cover a range of a few kilometres, but are limited by the need for optical visibility between the sensor and the fire. This is not a frequent situation in wooded and thickly vegetated areas. Moreover, the arrangement of several cameras to drive and acquire with continuity is an expensive solution in terms of maintenance, operation and installation costs. This type of sensor can also be displaced on aerial platforms (manned or remotely controlled aircraft). Even though advantageous for their ability of territory coverage, these sensors have significant limits of temporal continuity detection and degraded visibility of the fire front. Sensors transported in satellites can provide a very wide picture of the monitored area; this makes them effective for detecting fires in remote, unpopulated regions, where conventional fire monitoring is less intensive. Thick smoke plumes from forest fires, often extending several hundred kilometres, can also be identified by means of satellite imagery. On the other side, this technology cannot detect fires through thick clouds, so the total area of the satellite hotspots can represent only a certain percentage of the actual burned area. Also, the time lapse between retrieving and distributing the daily fire images may be very high, thus leading to a temporal resolution of these systems that is not satisfactory for forest fire management purposes and fire tactical operations. Fires can also be missed if they are not active at the time of satellite overpass or if they are small, of low intensity, or burning on the surface under the tree canopy.

\section{An innovative fire monitoring system: the EU-FIRE project}

A novel large scale forest fire long term monitoring system is being developed in the EU-FIRE project. It is an RTD project financed by the EC within the call FP6-IST IST-2005-2.5.12 ICT for Environmental Risk Management. The system will overcome the current limits through the exploitation of acoustic and optoelectronic technologies. It will consist (EU-FIRE Consortium [2]) of:

- A new design of acoustic system for volumetric scanning, consisting of a signal processing unit and one or more microphone arrays;

- A new design of fibre optic sensors networks and optoelectronic piloting units for the detection of changes in fire associated parameters, such as temperature and gaseous emissions; 
- A new control unit for data collection from sensor units as well as from traditional sensors, such as cameras and meteorological stations.

Acoustic sensors will be primarily used to detect fire noise from its very beginning. Thanks to the fact it does not need direct visibility, the acoustic system will be installed to continuously perform volumetric scanning in the monitored area. On the contrary, optoelectronic sensors are not power supplied, and do not need any maintenance. They will be installed kilometres away from the reading unit to provide more accurate information about the points where they are displaced.

\section{Description of a forest fire event}

A fire is the process of combustion in which a combustible material with an adequate supply of oxygen is subject to enough heat. Thus, three components are required for this process to start: a source of ignition (e.g. heat), oxygen, and fuel. Several parameters can define a typical scenario. A fire event can be described basically in terms of the type of burning vegetation. Herbaceous is a term used to define plants that have leaves and non-woody stems that die at the end of the growing season to the soil level in temperate zones. Litter is the top layer of the forest floor consisting of loose organic materials and fallen trees and plants elements. Slash indicates debris left as a result of natural events, such as wind, snow breakage, forest and other vegetation being altered by forestry practices and other human land activities (e.g. thinning and pruning, road construction, seismic line cleaning); it is a highly combustible fine fuel that ignites readily and consumes rapidly. Shrubs are low woody plants distinguished from a tree (which has one main stem, the trunk) by their multiple and permanent stems growing from a common base and lower height. Other important parameters are the fuel load (oven-dry weight of combustible materials per unit area) and its moisture content (which expresses the amount of water present in it). The meteorological conditions of the environment where a fire develops, i.e. precipitation, air temperature, relative humidity, wind speed, solar radiation, can determine the level of danger of a fire or the conditions to anticipate the ignition and the combustion. A scenario is also defined in terms of the topography (plane or inclined surface, canyon, valley) of the area where a fire develops.

\section{Acoustic characterization of a fire}

\subsection{Generality}

Noise generated by the combustion process of a $1 \mathrm{~m}^{3}$ wooded and brush material in free turbulence regime is mainly due to the shedding of vortex structures of the burnt areas at the base of the fire. These structures have been studied extensively (Detriche and Lanore [3]) and have been shown to be periodic with a frequency inversely related to the square root of the circumference of the burning fuel surface, covering the spectrum from about $1.0 \mathrm{~Hz}$ to $100 \mathrm{~Hz}$ as the effective diameter decreases from 2.0 to $0.02 \mathrm{~m}$. It is well known in literature that this part 
of the noise is very dependant on the size of the fire, type and state of fuel, and weather conditions. Another important aspect is related to the analysis of the time signal representing the pressure variations produced by the fire. Some specific events, called Acoustic Emissions (Wadley and Simmons [4]), can be found due to the microscopic change in stress generated by the heat and temperature gradient, which provoke mechanical modifications of the material. These events produce distinct acoustic pulses. If they repeat at a high frequency, as in the case of a great amount of burning fuel, crackling occurs.

\subsection{Experimental results}

An experimental campaign of acoustic measurements has been carried out in order to evaluate the frequency content and sound pressure levels produced by a fire event in different conditions. Laboratory tests and field tests were executed at the end of March 2007. The former campaign has been performed at the LEIF (Laboratory for Forest Fire Studies, an infrastructure created by ADAI to support experimental research on forest fires in Portugal) in Lousa (Coimbra, Portugal), while the latter has been performed at Lousa Airfield, close to the laboratory.

\subsubsection{Laboratory test}

The laboratory is equipped with several devices that are used to study, under controlled conditions, the main factors that can affect fire behaviour. During the laboratory tests, the Basic Rate of Spread Table and the Canyon Table (Figure 1) have been used. A preliminary evaluation of the reverberation time has been made, in order to determine the acoustic quality of the laboratory.

The acoustic measurements have been executed with a pressure-field microphone (located 2 meters far from the fire) and a digital tape recorder. For each test, a time history of 10 seconds has been extracted. Each signal has been
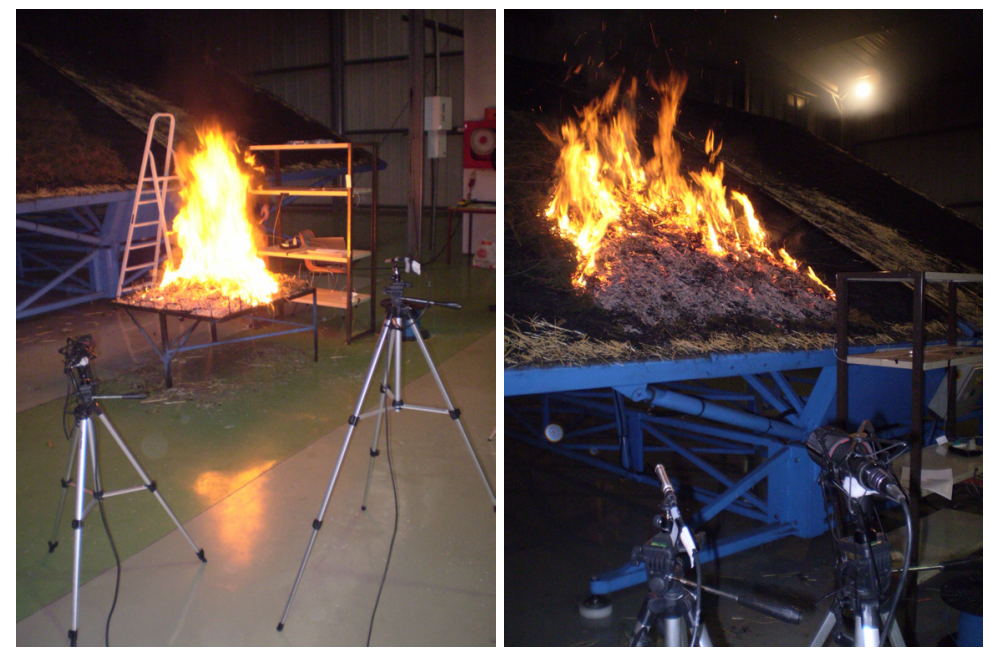

Figure 1: $\quad$ Fire plots used in the laboratory test. 
filtered (8th order band-pass filters with Butterworth characteristic in the frequency range $10 \mathrm{~Hz}-10 \mathrm{kHz}$, see Oppenheim and Shafer [5]) and acoustic features with constant percentage bandwidth technique have been extracted. The noise measurements have been analyzed for each different type of vegetation. The acoustic spectra, represented in 1/12 octave band, obtained for the different types of vegetation, are reported in Figure 2.

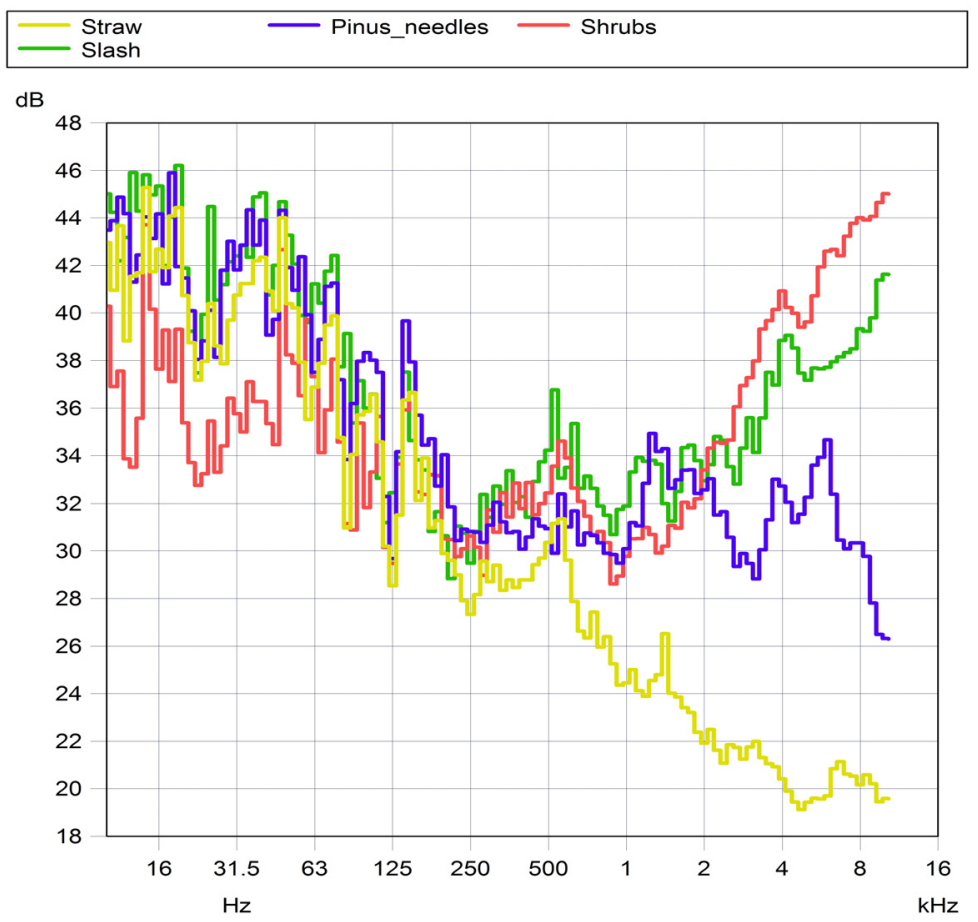

Figure 2: $\quad$ Acoustic spectrum in the laboratory test.

Data analysis demonstrated the high level of the fire noise emissions in the low frequency range $(0-500 \mathrm{~Hz})$ for all the vegetation tested. A significant level of noise in the high frequency range $(1-10 \mathrm{kHz})$ has been observed only for the shrubs cases. This is due to the crackling that, like impulses in time domain, has a wide frequency band of emission. These results confirm the main spectrum features available in literature and previously described.

\subsubsection{Field test}

The acoustic measurements have been executed with microphones located at different distances with respect to the 6 fire plots used. The positions of the fire plots and of the microphones are depicted in Figure 3. Data analysis has followed the same procedure adopted for the laboratory test. A fire plot and the microphone closest to the plots are depicted in Figure 4. For all noise measurements and for each type of vegetation, data analysis demonstrated 
(Figure 5) again the high level of the fire noise emissions in the low frequency range $(0-500 \mathrm{~Hz})$ and the same decay rate up to approximately $1 \mathrm{kHz}$. In this case an important level of noise emission at high frequency range $(1-10 \mathrm{KHz}) \mathrm{has}$ been observed for different trials. This is due to the contribution of the shrubs always contained in the fire plots. It can be noticed from Figure 5 that the sound propagation caused a slight attenuation in the low frequency range and a strong reduction of the high frequency contents in the fire noise emission. This is an expected result as the acoustic waves characterized by high frequencies undergo a greater attenuation related to air absorption.

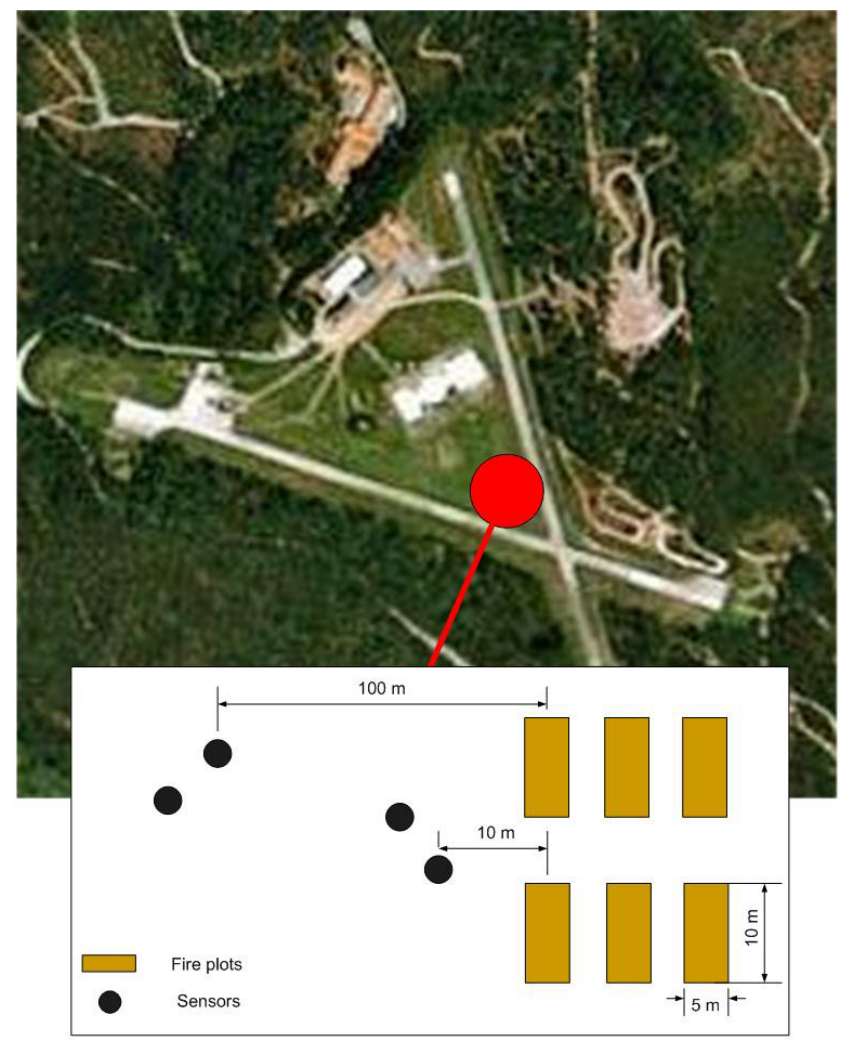

Figure 3: $\quad$ Plot and sensor positions in field tests.

A differentiation of the fire noise from other types of noise has been performed through the frequency representation. Spectrum evaluation has been made before the fire (just before the fire is started), during the fire, and after the fire (just after the fire died). The results obtained for (the login slash case) the closest and the further microphones are reported in Figure 6 and Figure 7. For all other tested fuels, it has been noticed that in low frequencies, i.e. between 200 and $500 \mathrm{~Hz}$ in most cases, the spectrum recorded during the fire is always higher 

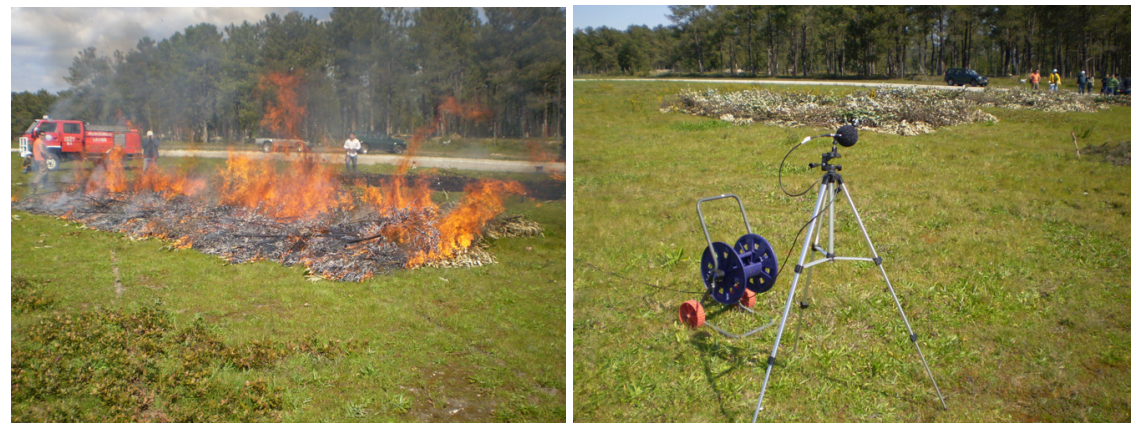

Figure 4: $\quad$ A fire plot and a sensor for field tests.

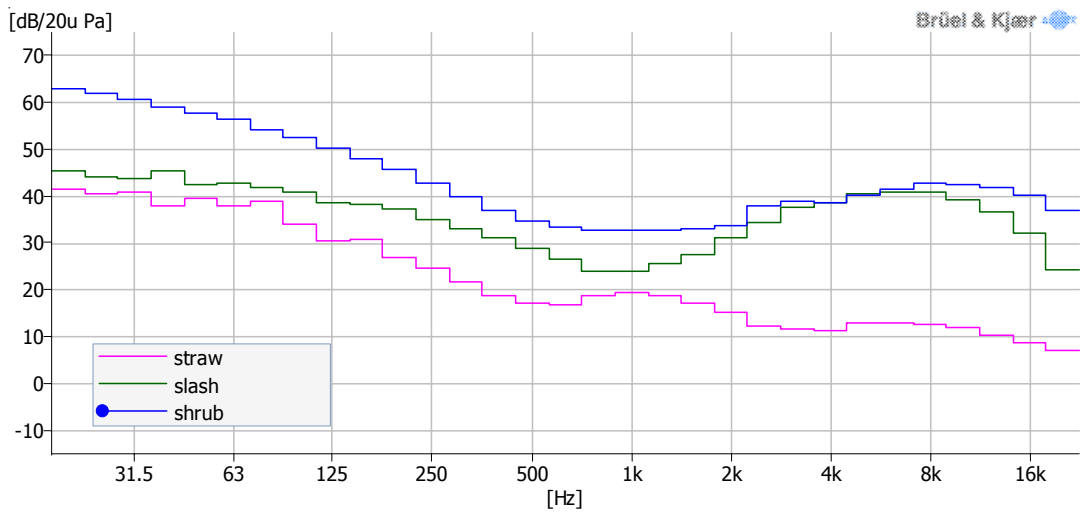

Figure 5: Acoustic spectrum in the field test.

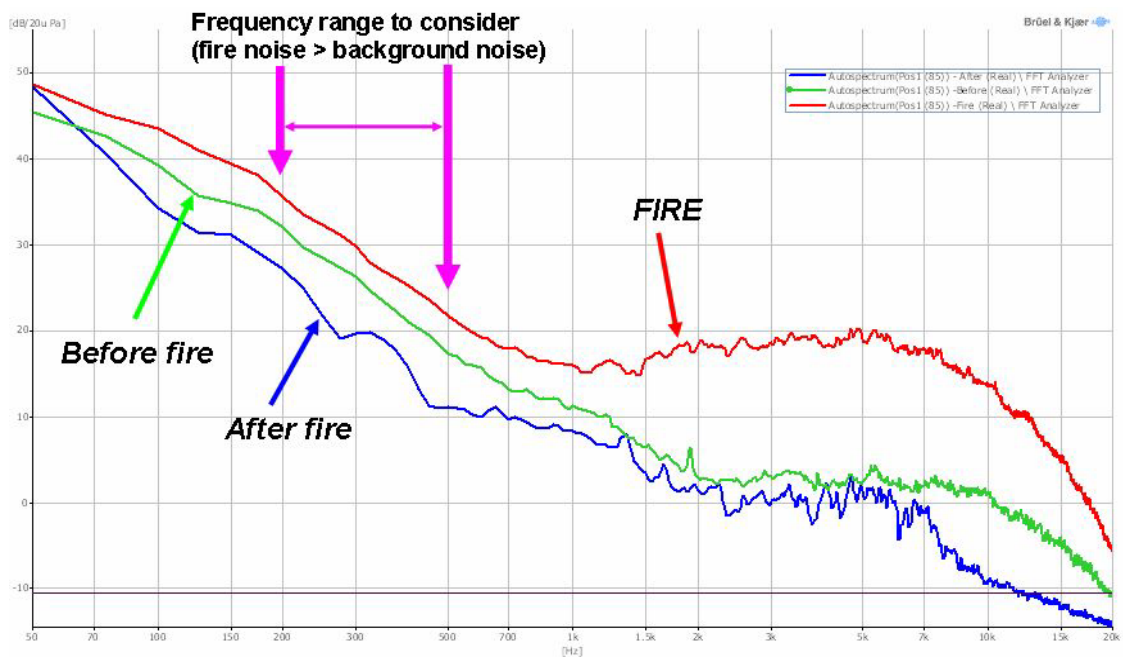

Figure 6: $\quad$ Fire vs. background noise (mic. at $10 \mathrm{~m}$ ). 


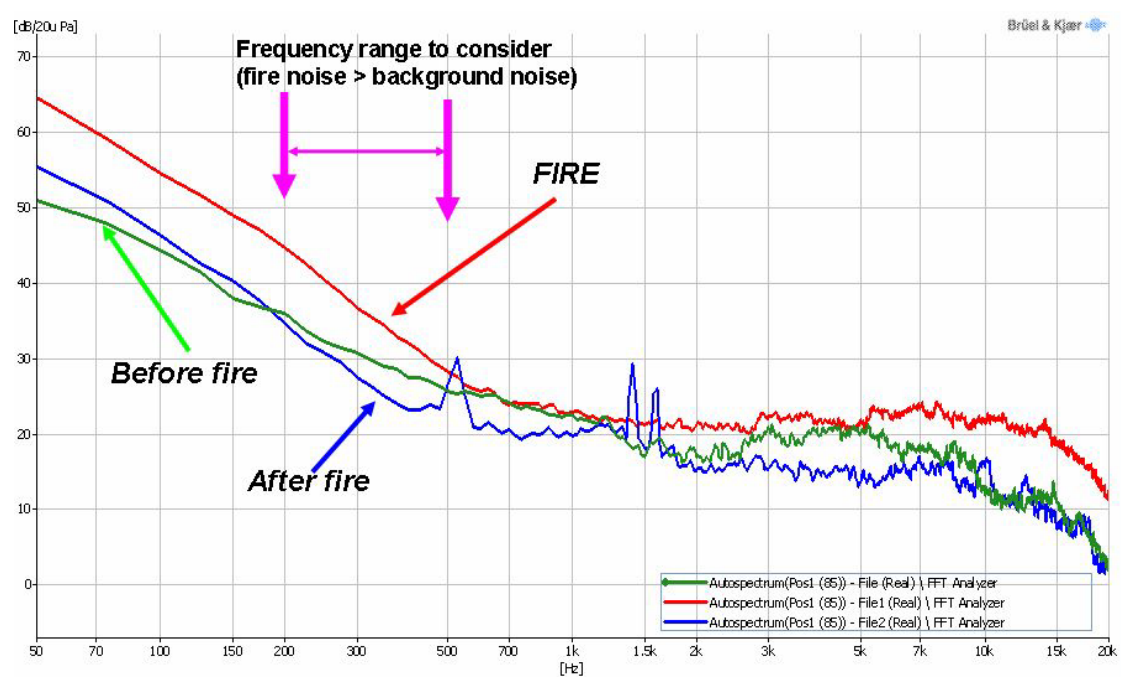

Figure 7: $\quad$ Fire vs. background noise (mic. at $100 \mathrm{~m}$ ).

than the spectrum of the background noise before and after the fire. Thus, the acoustic contribution of the fire is mainly concentrated in this frequency range, and it contributes more than the background noise. In presence of a background noise with high level, the fire noise could be masked (important wind speed, human activities, etc.): the combination of the signal filtering (on the frequency range $200-500 \mathrm{~Hz}$, for instance), the spatial filtering (beamforming) and the pattern recognition would give a better detection and recognition of the fire. All these components are programmed to be evaluated and implemented within the EU-FIRE project.

\section{Conclusions}

In this paper, an analysis about the acoustic emission and the relative frequency content of a combustion process has been performed. The analysis has been carried out on the basis of laboratory and field tests made in Lousa, Portugal. During the trials, it has been also evaluated the fire radiated heat to fibre optic sensors. The sensors have been put at a small distance to the plot or inside the fire plot. Thermocouples near the plot have been adopted to provide a reference measurement. The trials have been made in the context of the EU-FIRE project, which aims at the development of an innovative fire monitoring system based on acoustic and optoelectronic technologies.

\section{References}

[1] Radke L., Hegg A. et al., Airborne Measurements on smoke from biomass burning, 411-4222, 1988. 
[2] EU-FIRE Consortium, First Year Publishable Report, Doc. No. Deliverable D6, Iss. 2.0, 2008 (available from www.eufire.org)

[3] Detriche P. and Lanore J.C., An Acoustic Study of Pulsation Characteristics of Fires, Fire Technology, 16, 204, 1980.

[4] Wadley H. N. G. and Simmons J. A., Microscopic Origins of Acoustic Emission, ASNT Handbook on Acoustic Emission, NDT Handbook, Vol. 5, Section 3, Ed. P.M. McIntyre, 1987.

[5] Oppenheim A., Shafer R., Discrete-time Signal Processing, Prentice Hall, Englewood Cliff, NJ., 1989. 